\title{
FUTEBOL: DAS QUESTÕES DE GÊNERO À PRÁTICA PEDAGÓGICA
}

Aline Edwiges dos S. Viana

\section{Resumo}

O objetivo do presente estudo foi analisar a construção cultural do corpo feminino e verificar os preconceitos associados às questões de gênero quando o assunto é a prática do futebol feminino no Brasil. Para isto, levantou-se uma pesquisa bibliográfica de forma simples e objetiva percorrendo publicações acadêmicas nas temáticas, corpo, gênero e futebol. Optamos por discutir a condição dessa prática esportiva no âmbito escolar e a função mediadora do professor de Educação Física como um agente social e transformador dentro do contexto pedagógico.

\section{Palavras- Chave}

Futebol; Feminino; Educação Física Escolar; Gênero

\section{SOCCER: OF THE GENDER SUBJECTS TO PEDAGOGIC PRACTICES}

Aline Edwiges dos S. Viana

\begin{abstract}
The goal of this present study was to analyze the feminine's body cultural construction ad verify the preconceptions associates to question on the sort question when the subject is the practical of feminine soccer in Brazil. For this, a bibliographical research of simple and objective form was arisen covering academic publications in the thematic body, gender and soccer. We chose to discuss the condition of this sport practical in the scholar's ambit and the function of the teacher of Physical Education as a transforming social agent inside of the pedagogical context.
\end{abstract}

\section{Key-Words}

Soccer; Female; Physical Education School; Gender 


\section{INTRODUÇÃO}

O futebol é indiscutivelmente um esporte capaz de movimentar a nação brasileira durante os campeonatos mundiais, mais conhecidos como "copas do mundo". De uma simples prática esportiva que chegou por intermédio de Charles Miller, em 1894, tornou-se um fenômeno cultural, paixão nacional e é, uma referência mundial, quando falamos de Brasil, já que em qualquer campo, rua ou quadra nota-se garotos jogando e alguns sonhando em serem como seus ídolos, reproduzindo dribles e expressando a arte do futebol de Garrincha, Pelé, Ronaldo e Marta dentre outros mestres da bola.

Em virtude da cultura brasileira a mulher e o futebol passaram a ter caminhos opostos dentro da sociedade; caminhos trilhados e enraizados no chauvinismo machista. Assim, nos deparamos com diversas interrogações a respeito da prática do futebol, contudo, não são apenas interrogações que surgem, todavia afirmações em torno deste mesmo assunto aparecem e logo se fixam como verdades absolutas dentro do contexto sócio-cultural.

Não é raro observarmos idéias aglutinadas a homossexualidade e a feminilidade no esporte feminino, especificamente no futebol. Mas vestir calções, ter cabelos curtos ao invés de longos, calçar chuteiras ao invés de sapatilhas, ter hematomas e manchas nas pernas torna-se a praticante do futebol lésbica ou menos feminina que as demais mulheres que não praticam esse esporte?

Percebe-se que a interrogação discorrida no parágrafo anterior está fundamentada numa análise cultural, e conseqüentemente o fato do homem e da mulher se comportar diferente das expectativas sociais, no andar, falar, vestir entre outros procedimentos, já é motivo para serem julgados. Tendo como ponto de partida, portanto, que alguns dos ${ }^{1}$ julgamentos estão associados às relações de gênero e nas palavras de Scott (1995) deve ser analisado como uma categoria analítica.

Goellner (2001) chega ao consenso de que gênero é a construção social do sexo e o que diferencia homens e mulheres, não são apenas aspectos biológicos, mas sociais, históricos e culturais. Realçando esta idéia Altmann e Souza (1999) afirmam que determinadas culturas elegem e estabelecem suas construções para o feminino e o masculino.

Romero apud Oliveira (1996) menciona algumas construções sociais elegidas culturalmente para cada sexo

\footnotetext{
${ }^{1}$ Maneira, pela qual a sociedade se expressa e rotula os corpos quando existe algo que contrária as suas expectativas. 


\section{MENINO}

Ativo

Autoritário

Agressivo

Esportivo

Forte (fisicamente)

Independente

Machista

Autônomo

\section{MENINA}

Passiva

Dedicada

Elegante

Meiga

Responsável

Atraente

Vaidosa

Submissa

Scott (1995) salienta que as representações históricas do passado auxiliam na construção do gênero presente. Sendo assim, o peso da história da mulher em nossa sociedade é preponderante, quando tentamos analisar e justificar a situação do futebol feminino, primeiramente fragilidade física, maternidade e feminilidade são peculiares construídas no universo feminino. Assim, convém desnudar nas próximas linhas uma breve reflexão sobre a mulher brasileira, para alcançarmos o objetivo proposto.

Para compreendermos a situação da mulher no esporte e associarmos com percurso do futebol feminino no Brasil, é necessário identificar os personagens dessa historia, no caso, a mulher e o homem. No dicionário Brasileiro $O$ Globo compreende-se que mulher é:

- Pessoa do sexo feminino, depois da puberdade;

- Esposa, dama e senhora;

- Mulher à toa, mulher-dama, mulher da rua, mulher da vida, mulher do fado, meretriz;

E no mesmo material analisado conceitua o homem como:

- Animal racional;

- Ser humano do sexo masculino;

- Marido, amante, soldado, operário;

- Homem de Estado, homem de letras, homem publico, homem sanduíche; 
Como todos sabem, existem diferenças entre homens e mulheres, todavia não se encadeiam apenas em fatores biológicos. Assim, através desde determinante surgem conceitos e interrogações intrigantes em relação a esses personagens que residem na sociedade das gingas, do futebol, do carnaval, do samba, que talvez outrora chamássemos de sociedade brasileira.

Analisar a construção dos corpos masculinos e femininos passou a ser delimitado aos assuntos de gênero e nas ultimas décadas vem sendo discutido por vários estudiosos (as) de diversas áreas. É interresante o conceito dessa Historiadora feminista de que "o gênero é um elemento constitutivo de relações sociais baseadas nas diferenças percebidas entre os sexos e o gênero é uma forma primária de dar significado às relações de poder" (SCOTT, 1995, p.86).

Dentro da temática do futebol no Brasil, podemos observar as relações entre os gêneros, uma vez que essa modalidade é uma concepção de poder designada ao sexo masculino, que realmente é notório desde a infância, quando analisamos o universo feminino e masculino e o influxo dos agentes nas construções.

Daolio ressalta que:

Em torno de uma menina, quando nasce, paira toda uma névoa de delicadeza e cuidados. Basta observar as formas diferenciais de se carregar meninos e meninas, e as maneiras de os pais vestirem uns e outros. As meninas ganham de presente, em vez de bola, bonecas e utensílios de casa em miniatura. Além disso, são estimuladas o tempo todo a agir com delicadeza e bons modos, a não se sujarem, não suarem. (DAOLIO, 2003, p. 111)

O que se percebe é que, a educação que meninos e meninas obtiveram antes de inserirem na escola, reflete amplamente nas aulas de educação física com discriminações e preconceitos de gênero.

Encontramos em Mourão a seguinte conclusão "O esporte e a atividade física não fazem parte da realidade feminina brasileira; esse é um direito hoje que as mulheres não desfrutam por não ter sido educadas para isso" (MOURÃO, 2003, p. 144)

Não restam dúvidas de que a participação feminina no esporte gera manifestação, discriminações, preconceitos e questionamentos quando as mulheres são protagonistas das modalidades esportivas determinadas culturalmente como masculinas.

Goellner (2001) descreve que a inserção da mulher no esporte brasileiro teve influencias européias, e no inicio do século XIX surgiram às primeiras participações femininas no esporte que foram o turfe, atletismo e ciclismo. 
Notamos que a mulher iniciou-se no âmbito esportivo através dos esportes individuais e sem contato corporal, pois o contato físico poderia oferecer perigo para o seu corpo, já que alguns mitos e argumentos eram sustentados por médicos que tinham total domínio na Educação Física.

Nas primeiras décadas do século XX, o Brasil estava vivendo um processo de higienização, cujo objetivo era proporcionar vida saudável para o Estado. Assim, passou-se a preocupar com a maternidade e como criar e educar as crianças que nasciam. Associada a essa questão, na concepção dos médicos eugênicos, a atividade física passou a ser um conceito central para sustentar a ideologia de que para gerar crianças fortes e saudáveis para o país, era necessário realizar atividades físicas. Para isso, a Educação Física deveria fazer parte do cotidiano brasileiro, porém, os médicos privaram a mulher de alguns esportes que poderiam machucar principalmente os órgãos de reprodução.

Alguns esportes que não ofereciam tanto perigo eram recomendados. Neste caso, o voleibol, tênis e natação eram bem aceitos pelos especialistas. É importante ressaltar que no futebol, seguiu os mesmos princípios de outras modalidades, e alguns preceitos permanecem enraizados nos dias atuais como argumentos sustentáveis, ao tentarmos justificar a presença e a inserção da mulher nessa prática esportiva.

Assim, pensar no futebol como um fenômeno midiatico, social e cultural que não faz parte da realidade feminina na sociedade, é investigar as relações de gênero e poder dentro de um espaço social que nesse momento apresenta contingente insignificante da mulher brasileira protagonizando esse fenômeno futebolístico.

Partindo deste referencial, podemos analisar a situação do futebol feminino no âmbito escolar, principalmente nas aulas de Educação Física, onde ocorre preconceitos de raça, gênero e classe. E sendo, o futebol, um fenômeno cultural, deve estar presente no cotidiano escolar, uma vez que trabalhado nas aulas pedagogicamente, torna-se essencial para a formação cultural, motora e cognitiva dos alunos.

\section{OBJETIVOS}

O escopo deste artigo é analisar a construção cultural do corpo feminino, perpassando pelos preconceitos de gênero e as discriminações que surgem quando referimos à prática do futebol feminino no Brasil. $\mathrm{O}$ estudo faz uma reflexão sobre a função do professor como uma agente social essencial na transformação do futebol feminino no âmbito escolar. 


\section{MÉTODO}

Para realizar esta pesquisa optou-se por uma pesquisa bibliográfica, na qual obtivemos através de teses, dissertações, livros e artigos científicos informações para alcançarmos o objetivo proposto. Dividimos o trabalho em três temas centrais: Futebol, Gênero e Educação Física Escolar para compreendermos a realidade do futebol feminino e as influências dos agentes na construção dos corpos.

\section{RESULTADOS}

Constatamos que não é o futebol em si que está errado, mas a forma como ele vem sendo desenvolvido pelos professores. De fato se o desenvolvimento de técnicas e táticas for primordial nas aulas, a participação feminina será sempre mínima.

As meninas não possuem incentivo para o esporte durante a infância, não jogam bola, não sobem em árvores, não correm, ou seja, não realizam quando pequenas nenhuma atividade que beneficiará sua inserção ao esporte. Basta observar os brinquedos e as brincadeiras que permeiam a infância feminina fazendo com que a sociedade as identifique como fracas e inábeis ao esporte, principalmente no futebol. Utilizamos as palavras dessas autoras para compreendermos o significado da exclusão nas aulas:

"Não se pode concluir que as meninas são excluídas de jogos apenas por questões de gênero, pois o critério de exclusão não é exatamente o fato de elas serem mulheres, mas por serem consideradas mais fracas e menos habilidosas que seus colegas ou mesmo que outras colegas" (SOUSA; ALTMANN, 1999, p. 56).

Na mesma temática ${ }^{2}$ Daolio (2003) considera que "nem todas as meninas são inábeis e nem todos os meninos são hábeis. Existe uma enorme gradação entre o mais hábil e o menos hábil, tanto para as meninas quanto para os meninos. Além disso, essa gradação pode se modificar dependendo da atividade realizada".

Logo, o autor propõe uma Educação Física plural, a qual atinja todos os alunos, sem discriminação das meninas, dos gordinhos, dos menos habilidosos. Obviamente, para que a pluralidade venha acontecer, é necessário reavaliar as aulas, $\mathrm{j}$ á que todos os alunos se diferem dentro do grupo. Desta forma, as aulas devem possibilitar experiências motoras, para que todos explorem suas capacidades físicas, descubram novas expressões corporais e criem novas situações.

\footnotetext{
${ }^{2}$ DAOLIO, 2003, p. 108
} 
Analisando a questão feminina, cabe ao professor oferecer oportunidades para que as meninas venham usufruir da cultura corporal, isto é, jogos, esportes, danças, ginásticas e lutas. Assim, é fundamental que o futebol esteja presente no cotidiano feminino. De acordo com Sousa e Altmann (1999), a escola também constrói cultura; se por um lado os valores culturais afastam as meninas do futebol, é possível criar propostas pedagógicas para que as mudanças aconteçam e valores sejam ressignificados.

Não querendo ser cético, Daolio (2003) considera que os valores culturais e as construções culturais para homens e mulheres estão tão enraizados na dinâmica cultural de nossa sociedade, que não bastaria uma conscientização ou um desejo de mudança para uma possível transformação da realidade social.

E relevante trazer ao texto o comentário de Cardoso (1994) que:

\footnotetext{
"A ação do professor de Educação Física, por mais progressista que seja ainda não conseguiu se liberar da dicotomia criada culturalmente entre o masculino e o feminino, prosseguindo a atual ação pedagógica a limitar o pleno desenvolvimento motor dos indivíduos, norteada pelos atributos aceitos socialmente para cada sexo" (CARDOSO, 1994, p. 267).
}

Nesse sentido, Daolio diz que "os professores de educação física sentem dificuldades em se libertar de determinados preconceitos e propor uma pratica que propicie as mesmas oportunidades a todos os alunos, meninos e meninas, respeitando as diferenças e os interesses de cada um" (DAOLIO, 2003, p. $115)$.

Oliveira (1996) acredita que o professor de Educação Física seja a chave principal para que diversas questões venham ser debatidas nas aulas, pois dependendo da sua postura, da sua visão e opinião, poderá influenciar na formação dos alunos, criando condições justas e iguais para que cada um possa se desenvolver e experimentar diversas formas de movimentos corporais, a fim de que aprendam a lidar com as diferenças, discuti-las e interpretá-las no universo das aulas.

\section{CONCLUSÕES}

Através deste estudo vimos como a sociedade constrói o corpo feminino e assim constatamos que devido a está construção, as meninas são consideradas frágeis, passivas, submissas, embora meninas e meninos recebam as mesmas influências através dos agentes socializadores. Deste modo o futebol não faz parte da realidade feminina brasileiros, que se difere da masculina, por fatores culturais e não biológicos. Logo, sabemos que existem diferenças biológicas entre os sexos, mas não servem de argumentos para afastar a mulher do futebol. 
Ao considerar que os alunos quando ingressam na escola já estão revestidos de valores adquiridos em outros grupos sociais, concluímos que reverter à situação não e uma tarefa fácil para os professores. Todavia, o professor de Educação Física deve discutir através do futebol a situação da mulher na sociedade e mostrar aos alunos todos os preconceitos que existem em torno desta prática cultural.

Sendo assim, vimos que a finalidade do futebol nas aulas Educação Física não consiste na formação de jogadoras habilidosas, mas sim em conscientizar meninos e meninas de que o futebol é para todos, independentemente das habilidades motoras, sexo, raça ou cor, pois se o Brasil é o país do futebol e o mundo inteiro reconhece isso, as mulheres também são brasileiras.

\section{REFERÊNCIAS}

CARDOSO, F. O gênero e o movimento humano. Revista Brasileira de Ciência do Esporte, V.15, n.3, p. 265-8, 1994.

DAOLIO, J. Cultura: educação física e futebol. 2. ed. Campinas: Ed. da UNICAMP, 2003

FERNANDES, F. et al. Dicionário brasileiro globo. 47. ed. São Paulo: globo, 1997.

GOELLNER, S, V. Gênero, Educação Física e esportes: do que falamos quando em gênero falamos? In:VOTRE, S. Imaginário \& representações sociais em educação física, esporte e lazer. Rio Janeiro: Gama Filho, 200.

GOELLNER, S, V. A produção cultural do corpo. In: LOURO, Guacira (Org.). Corpo, gênero e sexualidade: um debate contemporâneo na educação. Petrópolis, RJ: Vozes, 2003.

OLIVEIRA, G. As aulas de Educação Física para turmas mistas ou separadas por sexo? uma análise comparativa de aspectos motores e sociais. 1996. Dissertação (Mestrado) - Faculdade de Educação Física, Universidade Estadual de Campinas, Campinas, 1996.

SCOTT, J. Gênero: uma categoria útil de análise histórica. Educação e Realidade, Porto Alegre, v. 20, n. 2, p. 71-99. Jul./dez., 1995

SOUSA, E.; ALTMANN, H. Meninos e meninas: expectativas corporais e implicações na educação física escolar. Cad. CEDES, Campinas, v. 19, n. 48, 1999. 


\section{Aline Edwiges dos S. Viana}

\section{Faculdade de Educação Física/Unicamp}

\section{Referência do artigo:}

\section{ABNT}

VIANA, A. E. S. Futebol: das questões de gênero à prática pedagógica, v. 6, p. 640-648, 2008.

\section{APA}

Viana, A. E. S. (2008) Futebol: das questões de gênero à prática pedagógica. Conexões, 6, 640-648.

\section{VANCOUVER}

Viana AES. Futebol: das questões de gênero à prática pedagógica. Conexões, 2008; 6: 640-648. 